\title{
Hospitalizations from car collisions twice as likely during evening
}

$\mathrm{M}$ ost hospitalizations caused by motor vehicle collisions from the Canadian Institute for Health Information (CIHI). The finding may yield benefits for prevention efforts.

Though driver hospitalizations as a result of vehicle collisions have steadily declined over the past five years, new data released Feb. 28 indicate that in 2010-2011 nearly 4000 drivers were hospitalized as a result of collisions that occurred between 4 pm and midnight.

That's nearly double the 2600 hospitalized as a result of collisions occurring between 8 am and 4 pm, and precisely double the 2000 hospitalized from midnight to 8 am.

"Our results highlight a pattern that can inform traffic collision prevention efforts," stated Greg Webster, director of primary health care and clinical registries at $\mathrm{CIHI}$.

Claire Marie Fortin, manager of clinical registries at the institute, says existing programs such as Safe Ride and Mothers Against Drunk Driving (MADD) can now focus their efforts on specific times in the day — as well as specific times of the year, such as holidays and long weekends.

CIHI focused its study on the drivers of vehicles "because it's their behaviour that we feel is the most amenable to change," says Fortin.

Although the number of hospitalizations from car collisions has decreased from 26000 five years ago to 22000 this year, the number is still substantial.

"To those 22000 people it is a major event in their life," says Fortin.

Preventing collisions can also yield benefits for the health care system. According to Fortin, about $\$ 300$ million is spent annually on hospital visits due to motor vehicle collisions. "The impact of these [collisions] is profound to the Canadian economic system." Sarah Spitz, CMAJ

CMAJ 2013. DOI:10.1503/cmaj.109-4427

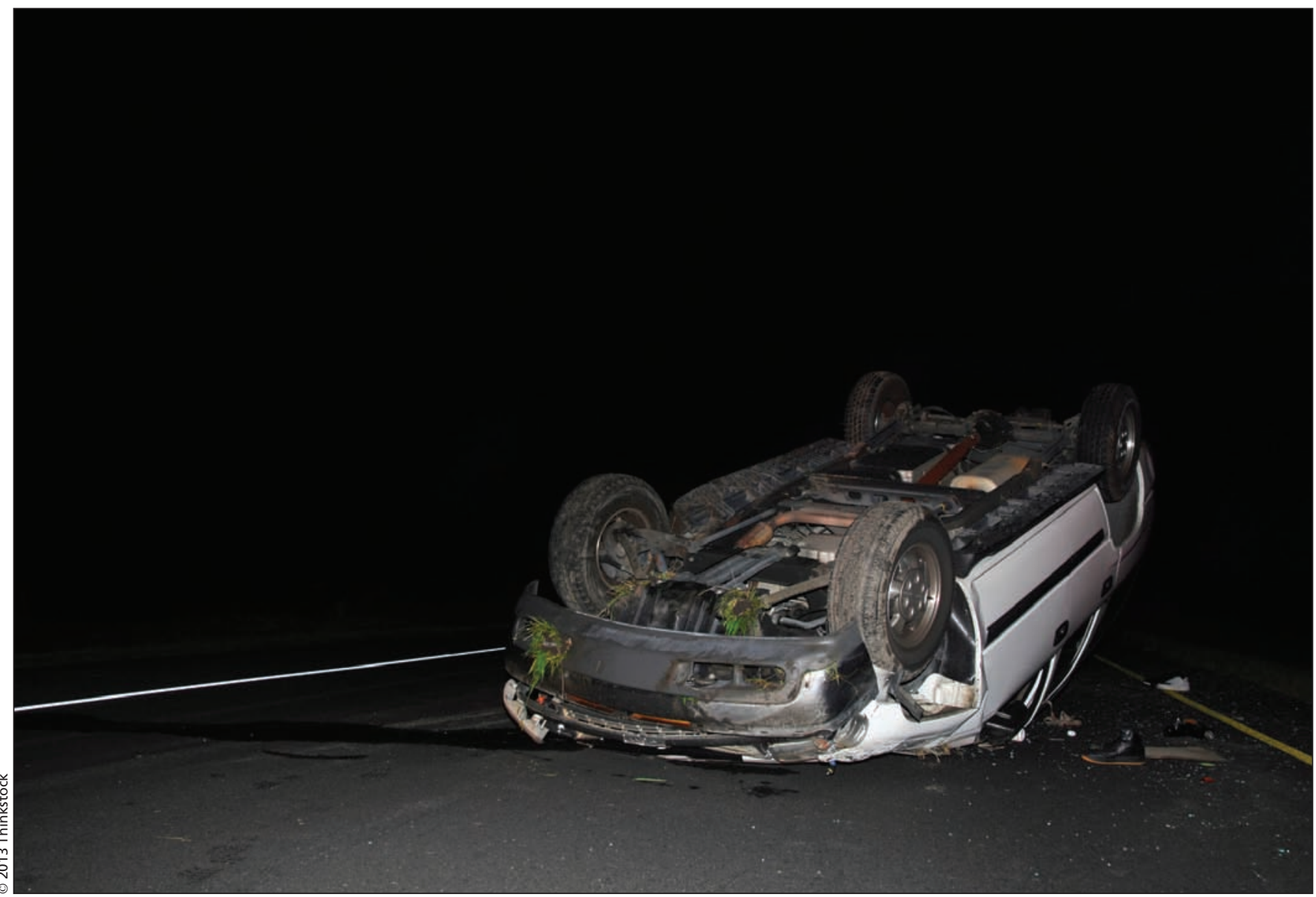

About $\$ 300$ million is spent every year in Canada on hospital visits due to motor vehicle collisions. 